\title{
O ECAD e o Direito de Execução no Brasil*
}

\author{
Carlos Alberto Bittar \\ Doutor em Direito pela Faduldade de Direito \\ da Universidade de S. Paulo.
}

\section{I - 0 direito de execução pública}

\section{Os direitos de autor: direitos patrimoniais}

Os direitos de autor compreendem prerrogativas de ordem moral e de ordem patrimonial, as primeiras relacionadas ao amparo de aspectos da personalidade do autor (o direito de dar à lume, ou não, a obra; o direito de modificá-la; o direito de adaptá-la ; o direito de retirá-la de circulação, dentre outros) e as últimas referentes à proteção de aspectos patrimoniais, na utilização econômica de sua criação (como, dentre outros, o direito de representação dramática; o direito de interpretação; o direito de execução; o direito de edição fonográfica; o direito de edição cinematográfica) (V. o nosso Direito de Autor na obra feita sob encomenda, S.P., R.T., 1977, p. 19 e segs.).

Os direitos patrimoniais decorrem da comunicação da obra ao público, que se perfaz de forma direta (sob a denominação geral de representação) ou indireta (sob a denominação geral de reprodução), por processos os mais variados, em função das diferentes expressões da arte humana e dos inúmeros aparatos técnicos existentes. De cada forma ou processo defluem, em razão de sua independência, direitos patrimoniais para o autor. Assim é que, para a composição musical, por exemplo, direitos decorrem, dentre outros, de sua gravação ; de sua interpretação; de sua execução pública, inclusive pela radiodifusão; de sua inserção em película cinematográfica, e assim por diante (V. a nossa obra cit., p. 27 e segs.; V. tb. Antonio Chaves: Proteção internacional ao Direito autoral de radiodifusão, São Paulo, R.T., 1.952, p. 351 e segs.; PEDro VICENTE BoBBio: $O$ Direito de autor na criação musical, S.P., Lex, 1951, p. 7 e 8).

* Conferência proferida no I Seminário Nacional do Serviço Jurídico do ECAD, no Rio de Janeiro, em 27-07-1981. 
Em virtude dos direitos patrimoniais - denominados também "direitos pecuniários" - a comunicação da obra ao público - que, normalmente, se faz por terceiros - depende de prévia e expressa autorização do autor (ou de seu representante legal), para o qual é carreada a respectiva retribuição econômica, consoante o sistema em que se insere.

Assim, como o autor não dispõe, à generalidade, de condições para proceder, por si, à comunicação da obra ao público, empresas e empresários de publicações e de espetáculos organizaram-se para tanto, pondo à sua disposição os meios necessários, mediante diferentes contratos de direitos autorais em que se sobressai o de cessão de direitos - que permitem abs seus titulares auferir a remuneração do capital empregado e ao autor a participação no resultado econômico obtido, na forma convencionada ou decorrente do sistema de arrecadação e distribuição existente.

Dessa forma, da utilização da obra advêm proventos para: a) o autor, assentados em direitos individuais reconhecidos ao criador, na defesa do homem de intelecto (V. o nosso $O$ Direito de Autor no plano das Liberdades Públicas, in "Justitia", n. ${ }^{\circ} 198$, p. 165 e segs.) e b) ao empresário, em razão do exercício de sua atividade e do lucro que a exploração da obra lhe propiciar. Ora, como a matéria-prima de sua atividade - para usar-se a terminologia empresarial - é a produção de espírito de outrem, ao autor deve corresponder a respectiva remuneração, sob pena de locupletar-se o empresário, indevidamente, com o fruto do trabalho intelectual daquele, conseqüência esta que, ao Direito, à evidência, repugna admitir.

Os direitos patrimoniais costumam ser divididos em duas grandes categorias: a dos denominados "grandes direitos", relativos à representação da obra, e a dos "pequenos direitos", referentes especificamente à execução musical (V PEDRO VICENTE BOBBIO: o. cit., p. 135).

\section{O direito de execução pública}

Dentre os direitos patrimoniais inscreve-se o direito de execução pública - em que nos concentraremos - o qual se traduz na prerrogativa que tem o criador de obra intelectual musical de a) autorizar a comunicação de sua criação ao público, por meio de vozes, instrumentos, ou aparelhos mecânicos ou eletrônicos (rádio, televisão e outros), recebendo, em conseqüência, b) os proventos econômicos correspondentes (V., dentre outros autores: EdUARDo PIOIA CASELLI: Trattato del Diritto 
di Autore e del contratto di edizione, Torino, Torinese, 1927, p. 444 e segs.; LUIGI DI FRANCo: Proprietà industriale, letteraria ed artistica, Milano, S.E.I., 1936, p. 735 e segs.; VALERIO DE SANCTIS: Contratto di edizione-contratti di rapresentazione e di esecuzione, Milano, Giuffrè, 1965, p. $381 \mathrm{e}$ segs.; PaOlo Greco e PaOlo Vercellone: I diritti sulle opere del'ingegno, Torino, Torinese, 1974, p. 135 e segs.; GEORGES STRASCHNOV: Le droit d'auteur et des droits connexes en radiodiffusion, Bruxelles, Bruyant, 1950, p. 105 e segs.; CHARLES DeBBash: Traité du droit de la radiodiffusion, Paris, Lib. Générale, 1967, p. 375 e segs.; e sobre a obra musical, HENRI DESBOIS: Le droit d'auteur en France, Paris, Dalloz, 1966, p. 116 e segs.).

$\mathrm{O}$ direito de execução consiste, pois, no direito decorrente do contato da obra com o público, por meio da expressão sonora, ou seja, da manifestação tendente a impressionar o sentido auditivo (V. PEDRo VICENTE BoBBIo: ob. cit., p. 16 e 17 e 64 e segs.).

Em face desse direito - que coexiste com outros direitos patrimoniais, como, por exemplo, os de edição gráfica, de gravação, de inserção em filme - qualquer processo de execução pública faz gerar "direitos pecuniários" (remuneração) ao autor, dependendo sempre de sua anuência a respectiva efetivação.

A autorização deve preceder à execução e perfazer-se por escrito, pelo próprio titular do direito, ou por seu representante legal.

Nesse passo, tendo em vista a existência de mecanismos de arrecadação por amostragem - ditada pela complexa e multifária rede de comunicação de obras intelectuais, que a tecnologia vem aumentando paulatinamente - a concessão da licença para execução tem-se operado por meio de associações de titulares de direitos autorais, que se têm formado - desde o início do processo de reconhecimento desses direitos, em fins do século XVIII - para, dentre outras atividades, facilitar a concretização das execuções (e outras utilizações da obra), eis que impossível ao autor proceder, por si, ao seu controle, não só no território de seu país, como no exterior (V., dentre outros escritores: ANTONIO CHAVES: ob. cit., p. 383 e segs.; Bоввіо : ob. cit., p. 133 e segs.).

Essas entidades, nascidas da própria necessidade da vida prática, administram os repertórios de seus integrantes - aos quais prestam serviços outros, inclusive de defesa de seus direitos - recebendo mandato, conferido pela legislação 
especial, pelo simples ato de filiação do autor (nesse sentido, a legislação brasileira, desde as primeiras manifestações: Dec. 5.492, de 16-7-1926, art. 28 e, atualmente, Lei 5.988, de 14-12-73: art. 104). Outorgam essas entidades, pois, aos usuários, em bloco, a autorização autoral para as execuções, simplificando, com isso, o processo de sua efetivação.

\section{Alcance desse direito}

O direito de execução pública compreende toda e qualquer comunicação sonora da obra com o público, realizada com intuito de lucro, direto ou indireto, por processo acabado.

Em razão de sua natureza e da diversificação dos processos e dos meios de comunicação da obra musical, o direito de execução pública é o mais importante para o autor desse gênero, apresentando diferentes especificações em consonância com a forma de utilização (assim, por exemplo, a execução pública por orquestra, ou por cantor, ou por aparatos mecânicos; a execução em rádio, em televisão, em cinema - e neste, também mediante a inserção na trilha do filme - e inúmeras outras).

Ora, em cada processo autônomo e acabado de comunicação pública existe, a par de outros, o direito de autor do compositor (musicista, ou letrista), que se expande progressivamente nos dias atuais.

Com efeito, tendo em vista a utilização crescente de música em diferentes atividades, desde as de recreação às de industrialização e de comercialização, esse direito assume hoje proporções verdadeiramente extraordinárias e, ao mesmo tempo, vem encontrando dificuldades em sua aceitação e, mesmo, em sua concretização, em certas áreas, principalmente pela falta de compreensão de certos usuários.

Para efeito de elidir-se eventuais dúvidas, algumas legislações costumam enunciar os usuários, ou pelo menos, indicar os locais e estabelecimentos em que ocorrem execuções públicas, mas sempre de modo exemplificativo, lobrigando, ademais, fórmulas gerais que abarcam os congêneres ou similares (nesse sentido, a lei brasileira, cit., art. 73 e $\S 1 .^{\circ}$; V., na doutrina, dentre outros autores, ROBERT PLAISANT: Le droit des auteurs et des artistes exécutants, Paris, Delmas, 1970, p. 107. No rol, estão, dentre inúmeros outros, os hotéis, "boites", locais dançantes, clubes, cinemas, teatros etc.).

Ora, em algumas atividades, a música é essencial e, mesmo, a própria razão da existência do meio de comunicação, como 
ocorre, por exemplo, com as emissoras de rádio (especialmente "FM"), de televisão, locais de danças e outras. Daí por que esses veículos devem proporcionar a maior parte da arrecadação do setor, em contrapartida, por meio de um sistema eficiente de cobrança e de arrebanhamento, não se justificando, portanto, as dissensões ainda observadas na prática. Se da música vivem e dela extraem a remuneração da atividade, justo é que se retribuam aos autores, com a satisfação de seus direitos patrimoniais!...

De qualquer sorte, o direito de execução pública está atrelado a todas as formas de comunicação sonora da obra, de caráter público e com intuito de lucro direto (recebimento de entrada, faturamento publicitário) ou indireto (remuneração de orquestra, de músicos).

Desse contexto apartam-se, como natural, as execuções privadas, ou sejam, as realizadas na esfera de atuação particular do interessado e as decorrentes de limitações impostas na legislação especial e ditadas pelo interesse público na difusão da obra (como, entre nós, as execuções de fonogramas e transmissões de rádio ou de televisão em estabelecimentos comerciais para demonstração à clientela; as efetivadas no recesso familiar, ou para fins exclusivamente didáticos nos locais de ensino, desde que não haja, em qualquer caso, intuito de lucro; as realizadas para prova judiciária ou administrativa: Lei 5.988/73: art. 49, incisos V a VII).

\section{II - Sistemas de arrecadação desse direito}

\section{Sistemas existentes para a arrecadação e a distribuição desse direito}

A fruição dos direitos de execução pública obedece a peculiaridades diferentes em todo o mundo (V. BOBBIo: ob. cit., p. 120 e segs.; ANTONIO CHAVES: $A$ arrecadação do direito de autor na Europa, relatório, em Revista da Faculdade de Direito, S.P., vol. LXVI, p. 393 e segs.; VALERIO DE SANCTIS: o. cit., p. 297 e segs.), mas que podem ser agrupadas em dois grandes sistemas: a) o de fixação de preço pelo autor, dependente de autorização do titular e b) o de determinação do Poder Público, em face de licença legal para execução (V. a respeito: CARLOS MoUCHET: El dominio público pagante, Buenos Aires, Fondo Nacional de las Artes, 1970).

Ocupar-nos-emos do primeiro, a que se integra o nosso país, salientando, de início, que pode comportar variações : a da auto- 
rização direta do titular, com remuneração autoral previamente ajustada entre as partes e a da autorização indireta (dos representantes, ou mediante programas), com retribuição dependente de pontuação (sistema de pontuação, ou também denominado, por alguns, "forfetário").

Verdadeiramente excepcional o primeiro como sistema único - podendo, no entanto, coexistir com o outro - tem-se na prática, pois, a consagração do sistema de pontuação, de modo universal.

Funda-se esse sistema no princípio da livre negociação entre os autores (ou seus representantes) e os usuários (ou suas entidades de representação), cabendo aos primeiros fixar - preço para a utilização de suas obras, que, normalmente, inserem em tabelas, para conhecimento geral (V., dentre outros autores : BoBBio : ob. cit., p. 126 e segs., em que demonstra que, nesse sistema, é subtraída, nessa fase, qualquer interferência do Poder Público; JACQues Chartier: Le droit du musicien sur son oeuvre, Paris, Lib. Générale, 1923, p. 180).

Esses preços costumam variar, em função de valores percentuais, ou fixos, de conformidade com as atividades e os locais em que se operam as execuções.

\section{O sistema de pontuação}

Consiste o sistema de pontuação em remunerar-se o autor em consonância com as execuções anotadas pelos mecanismos de coleta de dados. Atribuem-se pontos pelas execuções, com base nos quais recebe, ao final, o criador a sua retribuição.

Os preços para as utilizações são definidos em tabelas especiais, preparadas pelas associações de titulares e publicadas nos órgãos oficiais de comunicação, para conhecimento do público. Faz-se, também, divulgação das tabelas por outros meios, inclusive diretamente junto aos usuários.

Nas tabelas, a par dos preços, constam os critérios de cobrança e de aplicação, em razão da posição do usuário, ou da natureza do evento, levando-se em conta, ainda, a situação geográfica do local.

A coleta de dados perfaz-se por meio de processos eletrônicos e também manuais, como gravações, preenchimento de fichas (pranchetas), anotações e outros, procurando-se ora atingir-se grau maior de mecanização possível.

Segue-se o processamento interno na entidade arrecadadora, para efeito de posterior distribuição aos titulares, contra a apresentação da documentação correspondente. 
Verifica-se, ante ao exposto, que se trata de mecanismo complexo e que gera inúmeras dificuldades, desde a fase de taxação até a coleta de dados e o posterior processamento, apontadas, aliás, pelos doutrinadores, desde a respectiva origem (V BоввIо : ob. cit., p. 139), mas que, apesar de todas as vicissitudes, tem resistido e vem expandindo-se universalmente.

Acrescente-se, ainda, com respeito à cobrança, que os preços são fixados, sempre que possível, em consonância com o lucro direto, ou indireto, obtido pelos usuários. A base dos sistemas é a do número de execuções. Leva-se em conta, quanto aos usuários, a respectiva renda bruta, sobre a qual incide determinado percentual na tabela enunciado (como, por exemplo, na inserção de música em filme, a receita anual deste; em espetáculos teatrais, a soma obtida nas representações) (V. na doutrina, StRAschNov: ob. cit., p. 72 e segs.).

A cobrança utiliza agentes, que atuam diretamente junto aos locais em que se processam execuções, procedendo a gravações e a anotações.

A distribuição perfaz-se consoante critérios definidos pelas entidades arrecadadoras, respeitadas as normas legais e regulamentares existentes e com base nos cadastros que possuem dos titulares.

Existem, para o perfeito funcionamento do sistema, cadastros de usuários e de titulares e registros de obras, que possibilitam o processamento eletrônico da distribuição, utilizando-se, no pagamento, inclusive, estabelecimentos bancários credenciados.

Retêm as entidades arrecadadoras as verbas que lhes são deferidas, para a respectiva administração.

No nosso sistema, em que os usuários se dividem em "grandes" (estações de rádio, de televisão, "boites" e organizações de emissão de música) e "pequenos" (como os locais dançantes mistos, estabelecimentos comerciais e outros), os primeiros são obrigados à apresentação dos programas à autoridade de diversões públicas, com a prova da autorização autoral (desde, aliás, as primeiras normas do setor: Dec. 5.492, de 1928, art. 29 e Dec. 18.527, do mesmo ano; atualmente: Lei $5.988 / 73$ : art. $73, \S 2 .^{\circ}$ ).

A arrecadação de música está centrada em um Escritório Central, constituído pelas associações de titulares, o ECAD, ora em processo de reformulação e aperfeiçoamento. 


\section{A atuação das associações de titulares}

Ocupam posição de destaque na arrecadação e na distribuição de direitos de execução as associações de titulares (denominadas, ainda, "sociedades de autores"), cuja história se identifica com a do próprio Direito de Autor.

Com efeito, surgidas na França, à época em que começou a fermentar a luta pelo reconhecimento dos direitos dos autores, essas entidades contribuíram decisivamente para a sua implantação prática (V., dentre outros autores: Nicola STOLFI: Il Diritto di Autore, Milano, s.E.I., 1932, v. 2, p. 788 e segs.; MARIE ClaUdE Dock : Etude sur le droit d'auteur, Paris, Lib. Générale, 1963, p. 143 e segs.; CHAVEs: Proteção..., ob. cit., p. 386 e segs.; BовBIо : ob. cit., p. 133 e segs. Ressalta-se, nos estudos a respeito, a atuação de RICHELIEU e BEAUMARCHAIS, que procuraram reunir os intelectuais que lutavam por seus direitos. Outrossim o movimento começou com os autores dramáticos, na sociedade conhecida pela sigla "SACD" e, em seguida, com os de música, na "SACEM", em 1829 e 1851, respectivamente).

Nascidas do espírito associativo - exemplo depois retomado pelos trabalhadores manuais, na denominada "Revolução social" - conseguiram, pela união de forças das categorias interessadas, fazer valer, em concreto, os direitos de seus associados, atuando sob todas as formas juridicamente possíveis.

A reunião deu-se, em princípios do movimento, por classes de titulares de direitos, a saber, autores dramáticos entre si, compositores musicais de outro lado, escritores em outra entidade, e assim por diante, dentro, aliás, do espírito de formação classista, que mais tarde veio a aproximar os diferentes trabalhadores na batalha pela conquista de seus direitos trabalhistas.

Mas, aos poucos foram aparecendo também entidades híbridas, congregando titulares de categorias de direitos distintas, em função da necessidade de maior aglutinação de forças, desde que sempre se manifestou, em oposição ao pagamento desses direitos, o complexo empresarial usuário, dentro da eterna luta entre o capital e o trabalho, que marca a crise do mundo moderno (V. a respeito, o nosso artigo: $O$ dirigismo econômico e o direito contratual, in R.T., 526/20) (V. tb. Bовві0: ob. cit., p. 121 e 142).

Daí porque, com a evolução dos tempos, em alguns países implantaram-se diferentes associações, obedecido o critério de categorias, ou não (ou seja, diversas associações do mesmo gênero), ou subsistiu apenas uma, na representação de todos os intelectuais com obras protegidas (V., dentre outros autores: 
STOLFI : ob. cit., p. 739 e segs.; GRECO e VERCELLONE: ob. cit., p. 350 e segs.; DE SANCTIS : ob. cit., p. 303 e segs.; PlaisANT: ob. cit., p. 104; AlAIN LE TARNEC: Manuel de la propriété littéraire et artistique, Paris, Dalloz, 1966, p. 166 e segs.; Boвbio: ob. cit., p. 132 e segs.; CHAVES: ob. cit., p. 390 e segs.; ROMEO GROMPONE: El derecho de autor en Uruguay, Montevideo, AGADU, 1977, p. 187 e segs.; RICARDo ANTIQUERA PARILLI: Consideraciones sobre el derecho de autor, Buenos Aires, ed. próp., 1977, p. 253 e segs.). Assim, por exemplo, e enunciadas por suas siglas, temos: na Inglaterra, a I.S.A.P.C.; na França, a SACEM (música) e a SACD (autores dramáticos); nos EE.UU., em que há pluralidade, mesmo setorial, destaca-se, dentre outras, a ASCAP, de New York; na Itália, a SIAE (com exclusividade em direitos autorais e conexos) ; na URSS, a VAAP (global e exclusiva); na Espanha, a SGAE (exclusiva); na Argentina, a SADAIC (exclusiva em música) e a ARGETONES (para obras dramáticas) e a SADE (de escritores); no Uruguai, a AGADU (exclusiva em música); na Alemanha, a GEMA (exclusiva para música), a GVL (dos produtores fonográficos e artistas executantes) e a VG WORT (das obras literárias), e assim por diante (V. tb. a respeito, CHAVES: $A$ arrecadação, cit., em que mostra o funcionamento $\mathrm{e}$ os expressivos índices de arrecadação das sociedades européias).

Quanto ao respectivo regime jurídico, em alguns países dependem de autorização estatal para constituição e funcionamento, enquanto em outros dispõem de liberdade para tanto, sofrendo, no entanto, a fiscalização do governo, além da geral de todo o sistema (como natural) (v. autores e obras acima citados).

As associações procedem à arrecadação de direitos nos respectivos países, recebendo as verbas do exterior - dada a extraordinária difusão das obras musicais - por intermédio de suas congêneres e mediante contratos de reciprocidade que com elas firmam, existindo, inclusive, no plano internacional e como entidade de congregação e fiscalização de sociedades, a CISAC (desde 1927), sob o regime de confederação de associações.

As verbas são remetidas pelos meios ajustados, sofrendo, conseqüentemente, os influxos das legislações dos países envolvidos, inclusive sob os aspectos de controle e de tributação, existindo, no entanto, tratados tendentes a evitar a bitributação dos direitos autorais (V. a respeito, o nosso trabalho $A$ tributação dos direitos autorais, a ser publicado pela Revista da Faculdade de Direito da USP). 
No Brasil, tem-se sistema complexo: as associações são dependentes de autorização estatal e a arrecadação musical está afeta ao referido "bureau" central, existindo pluralidade de entidades, mesmo a nível de categorias, como a seguir veremos.

\section{III - O sistema brasileiro: o ECAD e o poder exclusivo de arrecadar esse direito}

\section{Antecedentes}

Inobstante existam disposições legais sobre direitos autorais já em fins do século passado (a primeira Lei, n. ${ }^{\circ} 496$, de 1-8-1898), foi somente a partir da edição do Código Civil em que se dedicou um capítulo à matéria (arts. 649 e segs.) que a sociedade brasileira se conscientizou da existência desses direitos, surgindo então o movimento de instituição de associações de titulares (chamadas "sociedades de autores").

Iniciado em 1917 com a SBAT (na ocasião, congregando, de início, os autores teatrais, e, logo em seguida, também compositores musicais), o movimento expandiu-se depois, surgindo, ao longo dos tempos, outras entidades, mediante, principalmente, desmembramentos das existentes, em virtude de dissensões entre os interessados. Assim é que, em 1938, os compositores desligaram-se da SBAT para formar a ABCA (Associação Brasileira de Compositores e Autores), enquanto aquela (Sociedade Brasileira de Autores Teatrais) voltava às origens, mas mantendo um departamento musical. Os seus componentes, no entanto, desligaram-se em 1942, fundindo-se na citada ABCA para formar a UBC (União Brasileira de Compositores). Em 1946, nascia a SBACEM (Sociedade Brasileira de Autores, Compositores e Editores), em virtude de divergências entre editores e autores na UBC. Em 1956, outra entidade apareceu, a SADEMBRA (Sociedade Arrecadadora de Direitos de Execuções Musicais no Brasil). Deu-se, ainda, em seguida, a constituição de uma coligação, denominada Coligação das Sociedades de Autores, Compositores e Editores, em face dos problemas existentes para a arrecadação. Em 1960, fundou-se a SICAM (Sociedade Independente de Compositores e Autores Musicais), em face do descontentamento de compositores de São Paulo quanto ao sistema existente.

Cinco sociedades passaram, então, a atuar, surgindo daí dificuldades para a cobrança, com as entidades disputando entre si o poder de receber os recursos correspondentes, com prejuízos para todo o sistema. Tomaram a SBAT, a UBC, a 
SADEMBRA e a SBACEM a iniciativa de constituir um escritório central de arrecadação, por elas controlado, que se chamou SDDA ("Serviço de Defesa do Direito Autoral").

Dele não participou a SICAM e, ao revés, continuaram a aumentar os problemas da arrecadação, em virtude da própria complexidade do mecanismo. Entrementes, com a regulamentação dos direitos conexos (de artistas, intérpretes e executantes e produtores de fonogramas), surgia, em 1967, a sOCIMPRo (Sociedade Independente de Intérpretes e Produtores de Fonogramas) para atuar nessa área.

As dificuldades enfrentadas então, reclamações de autores, resistência de certos usuários, problemas na arrecadação e na distribuição de valores, fizeram com que surgissem defensores da edição de um Código de Direitos de Autor e Direitos Conexos, em que se inserisse toda a legislação esparsa e se previssem instrumentos de controle, pelo Estado, da atuação das sociedades, bem como a unificação da cobrança.

Depois de estudos e discussões, expediu-se a Lei 5.988, de 14-12-73, que criou, para a regência do setor, o Conselho Nacional de Direito Autoral (CNDA) e, para a centralização da arrecadação, o Escritório Central de Arrecadação e Distribuição (ECAD), constituídos, efetivamente, bem depois (início de 1976 e 1977).

\section{A criação do ECAD e o sistema decorrente da Lei 5988 , de 14.12 .73}

Com o advento da Lei 5.988/73, a par da criação das entidades referidas (arts. 116 e 115, respectivamente), passaram as sociedades a denominar-se "associações de titulares", recebendo ampla regulamentação (arts. 103 a 114) e a incumbência de organizar o ECAD, e ficando dependentes de autorização para funcionamento, com regras emitidas pelo CNDA.

Mas, o Conselho então instalado resolveu regular a formação do ECAD, impondo, em sua composição, integrantes do Poder Público (Resolução n. ${ }^{\circ}$ 1, de 6-4-76), tendo, no entanto, por via judicial, as sociedades obtido para si a constituição do Escritório, que passou a reunir os titulares da área musical. Por via de acordo, a SBAT continuou a recolher os direitos no setor teatral.

Novas associações sobrevieram ao depois, estando ora autorizadas a funcionar (a par das citadas) : a ASA (Associação de Atores) (intérpretes, dubladores e artistas em geral) ; SABEM (Associação de Autores Brasileiros e Escritores de Música); 
Assim (Associação dos Intérpretes e Músicos) ; AMAR (Associação de Arranjadores e Músicos); e ANACIM (Associação Nacional de Compositores, Intérpretes e Músicos) (a dos artistas nasceu com a regulamentação da profissão: Lei 6.533 , de 24-5-78).

O ECAD entrou a funcionar em 1977, preocupando-se com a execução musical especificamente e, para isso, instituindo sistema de processamento eletrônico das pontuações e dos pagamentos, centralizados na Caixa Econômica Federal.

Sediado em Brasília, com núcleos operacionais em São Paulo e no Rio de Janeiro e agentes e representantes em outras capitais, empreendeu o ECAD o processo de unificação da cobrança dos direitos de execução musical.

Instituído sem finalidade de lucro, deve submeter-se a estatuto aprovado pelo CNDA (Lei cit., art. 115), além de cumprir, junto ao citado organismo, as demais obrigações a que também se sujeitam as associações (arts. 113 e 114).

A partir de sua efetiva atuação, em 1-1-77, as associações passaram, com respeito à arrecadação, a desempenhar o papel de meras repassadoras de verbas recolhidas ao ECAD, com a participação definida na regulamentação referida (Resoluções do CNDA), para o cumprimento de suas finalidades (Resoluções $n .{ }^{\circ}$ s 1 , de 6-4-76, sobre o estatuto do ECAD; e 6, de 25-11-76, que a modificou; n. ${ }^{\circ} 3$, de 20-4-76, que fixou prazo para as associações arrecadarem, até $31-12-76$; e n. ${ }^{\circ} 8$, de 22-12-76, que lhes definiu o percentual participativo).

Assim, em face da sistemática estabelecida pela Lei 5.988/ 73, ocorreu, entre nós, a centralização da arrecadação de direitos de execução musical, já esboçada, por iniciativa das próprias interessadas, no mencionado SDDA. Deixaram então as sociedades de arrebanhar os recursos advindos da execução musical, ficando apenas a SBAT arrecadando na área teatral em termos de associações e, inobstante as falhas e dificuldades, problemas e reclamações, a verdade é que - aqui como alhures - contribuíram elas, de forma decisiva, para a implantação prática dos direitos autorais no Brasil.

O novo sistema - sob controle, assistência e físcalização do CNDA, vinculado ao Ministério da Educação e Cultura coloca o nosso país em posição de intervencionista no setor, a exemplo de outros tantos em que o Estado vem ocupando lugar (V. o nosso citado trabalho $O$ dirigismo econômico e o direito contratual). 
Consolidou-se com o ECAD a unificação no setor musical, para a arrecadação, institucionalizando-se métodos e processos novos para esse fim e para a distribuição dos valores obtidos, sob a égide da computação. Adotou-se o sistema de pontuação também - usado antes pelas associações - e assentaram-se os preços, reajustáveis periodicamente, nos critérios definidos pelo CNDA, dando-os a luz por meio de tabelas publicadas e divulgadas na forma exposta (Res. CNDA n. ${ }^{0}$ 7, de 15-12-76 e, atualmente, $n .^{\circ} 24$, de 11-3-81).

\section{Exclusividade do poder de arrecadação do ECAD}

Assim, a partir da Lei 5.988/73 e, na prática, de sua regulamentação referida (1-1-77, precisamente), o ECAD detém, entre nós, a exclusividade do poder de arrecadação e de distribuição, verbis, "dos direitos relativos à execução pública, inclusive através da radiodifusão e da exibição cinematográfica das composições musicais ou lítero-musicais e de fonogramas" (art. 115, "caput", da lei) .

Com isso, às associações, que do Escritório recebem as verbas de seus associados, ficou reservada, nesse passo, função de repassadoras de direitos, a par de atribuições outras que da lei e de seus estatutos defluem, inclusive na defesa dos direitos de seus integrantes (arts. 103 e segs.).

Não se exclui, outrossim, a possibilidade de o próprio autor exercer, pessoalmente, os seus direitos (art. 114, parágrafo único), faculdade que muitos titulares têm feito valer, inclusive mediante filiação direta ao ECAD.

Posição singular nesse contexto ocupa a SBAT, que arrecada na área teatral, tendo firmado convênio, quando da instalação do ECAD, para continuar nesse mister.

Discute-se, no entanto, a propósito dessa colocação, em face de disposições contidas na própria Lei 5.988/73 (arts. 115 e 73 e $\S 2 .^{\circ}$ ), especialmente após a ampla reformulação por que passaram o CNDA e o ECAD, já sob o atual governo, pois em verdade, está em jogo a própria exclusividade conferida à central arrecadadora.

Com efeito, preocupado com os problemas existentes no setor - eis que o Conselho instalado, a par de não contar com especialistas na matéria, estava voltado totalmente para a área musical, inobstante a importância de outros setores culturais, que reclamavam atuação específica - determinou o governo do Presidente FigUEIREDo a realização de estudos para a reor- 
ganização do CNDA, que acabou por concretizar-se no Dec. 84.252, de 28-11-79, que trouxe para a sua composição técnicos e estudiosos de Direito de Autor, a par de uma estruturação mais abrangente, para abarcar todas as diferentes manifestações estéticas do gênio humano.

Empossado em abril de 1980, o novo Colegiado deu início, ante a estudos realizados, a medidas tendentes ao aperfeiçoamento do setor e ao aprimoramento das técnicas de arrecadação e de distríbuição de direitos autorais, voltados agora para uma visão sistêmica dessa área, e sob a perspectiva de proteção maior ao criador intelectual.

Dentro desse espírito, determinou o CNDA a reestruturação administrativa do ECAD, dotando-o de organização condizente com a evolução ocorrida e com as importantes funções que deverá desempenhar, de modo contínuo, em prol dos titulares de direitos, por meio da Resolução CNDA n. ${ }^{\circ} 19$, de 14-5-80, adotando, em seu contexto, após inúmeras discussões, a tese da centralização, no ECAD, de todos os direitos autorais (art. 30 e parágrafo único), na execução e na representação.

As associações existentes procuraram, de imediato, integrar-se, no prazo conferido ao ECAD - que preparou o novo estatuto, sob a orientação do CNDA, que o aprovou (Resolução n. ${ }^{\circ} 20$ ), depois de ampla análise - com exceção da SBAT, que se insurgiu contra a decisão, interpondo recurso ao Ministro da área, que foi acolhido, tendo, em conseqüência, perdido a eficácia a Resolução n. ${ }^{\circ}$ 19/80.

Rediscutida a matéria pelo CNDA, foi baixada a Resolução n. ${ }^{\circ} 21$, de 2-10-80, que, praticamente, reeditou a de n..$^{\circ} 19$, e, como a solução do problema da SBAT fora confiada a Grupo de Trabalho especialmente nomeado, excluiu-se de seu contexto, a arrecadação sobre as obras dramáticas, determinando-se que se aguardariam os resultados desse trabalho, para um posicionamento final do CNDA.

Mas, seja como for, pairam dúvidas quanto ao alcance da competência do ECAD, a respeito de obras de outros gêneros, em razão de disposições inseridas - como assinalamos - na própria lei de regência.

Com efeito, se, de um lado, no texto específico em que criou o ECAD, a Lei 5.988/73 fala em "composições musicais e lítero-musicais", no relativo ao direito de execução e de representação (de caráter geral) inclui "drama, tragédia, comédia" e outras obras (arts. 115 e 73, respectivamente), subordinando a utilização ao recolhimento das verbas autorais ao $\mathrm{ECAD}$ (art. $73, \S 2 .^{\circ}$ ). 
A respeito, duas teses existem - e foram debatidas no CNDA - a) a de que, no âmbito do ECAD, podem inserir-se todas as obras e titulares de direitos e b) a de que, ao revés, em seu contexto se inserem apenas as obras musicais, em face da especificidade que a lei quis imprimir - como sustentam ao Escritório. Para a primeira, o ECAD seria o canal único de ingresso de valores, sem mesclagem, no entanto, de sistemas (podendo manter-se o das obras teatrais, de recepção e distribuição direta, por meio da departamentalização do ECAD fixada na sua reestruturação. Para a segunda, deveria cuidar apenas das obras musicais, permanecendo as da área teatral sob a regência da SBAT (V a respeito, o nosso artigo Arrecadação para os direitos de autor, em "O Estado de São Paulo", de 27-6-80, p. 31).

A tendência, no entanto, é para uma central arrecadadora única, já composta, aliás, muito antes da lei, pelas próprias associações (inclusive a SBAT), pela convergência de forças maiores no organismo e o seu conseqüente fortalecimento, na difícil luta de aperfeiçoamento e de implantação efetiva desses direitos.

De fato, se - como afirmam alguns (embora também discutível a assertiva) - o espírito que presidiu a edição da Lei 5.988/73 foi a da instituição de um organismo arrecadador específico para a música, a própria evolução demonstrou o contrário, porque entidades outras, de área não musical, vieram a integrar-se ao Escritório, que na nova regulamentação acabou por abarcar também os direitos conexos, em razão do próprio espírito da Lei 5.988/73, e do Dec. 84.252/79, que ampliou à esfera de competência do CNDA, nela incluindo todos os direitos autorais reconhecidos (de autor e conexos) e de obras de todos os gêneros.

Remontando-se, outrossim, às discussões que precederam à edição da Lei 5.988/73 e à própria situação fática, verifica-se, efetivamente, que estava em germinação a idéia de uma central única - que, no projeto de Código de Direitos de Autor e Direitos Conexos, de 1967, se concentrava em um Escritório Central, com o nome de ECA, revivendo-se, praticamente, o SDDA, agora, porém, sob a fiscalização estatal, mesmo porque as associações não visam lucros $(\mathrm{V}$ a respeito: ANTONIo CHAVES: O projeto brasileiro do Código de Direito de Autor. e Direitos Conexos, em "Revista da Faculdade de Direito", S. Paulo, v. LXVI, p. 105 e segs., espec. p. 135 e segs.) desde que os próprios interessados se convenceram de que isso representaria fator de fortalecimento da cobrança, em vista do 
inconveniente da multiplicidade de entidades arrecadadoras e das dificuldades encontradas junto aos usuários.

Com a centralização, ter-se-ia o fortalecimento do Escritório, a minimização de custos operacionais, o aperfeiçoamento dos mecanismos de cobrança, a facilidade de identificação junto aos usuários, tudo em prol dos próprios autores e titulares de direitos e, enfim, da própria cultura geral do país (como assinalamos no artigo ult. cit.). Nesse sentido é a doutrina especializada (V. BobBio: o. e loc. já citados; Chaves: Proteção, cit., p. 405).

A matéria será, oportunamente, definida, com a conclusão dos trabalhos referidos, cabendo-nos, outrossim, reafirmar que, no sistema vigente, o ECAD detém a exclusividade na arrecadação proveniente de execução musical (e em áreas de direitos conexos, de artistas e de outros que aderiram ao Escritório), tendo as associações que recebiam direitos - exceto a SBAT - cessado, em 31-12-80, essa tarefa, por força da Resolução CNDA n. ${ }^{\circ} 21 / 80$.

Assinale-se, outrossim, que o ECAD é - a exemplo das associações - constituído mandatário de suas integrantes (Res. cit., art. $4 .^{\circ}$ ), revestindo-se da forma jurídica de associação de associações - portanto, de cunho privado - mas sob a égide do CNDA.

\section{IV - A submissão do ECAD ao CNDA}

\section{Estruturação anterior do setor de direitos autorais}

Como assinalamos, a conscientização dos direitos autorais e a conseqüente estruturação do setor assumem foros de realidade a partir da consagração desses direitos em nosso Código Civil.

Iniciou-se, então, a formação de associações de titulares, dentro do modelo tradicional e, daí em diante, começa a engrenar-se uma estruturação para a sagração prática desses direitos, ante ao império de extensa legislação especial que se vai expedindo, a partir, principalmente, de 1928 (Dec. 5492 e 18527, ambos daquele ano).

Nessa estruturação, atores principais são as associações ("sociedades") e seus representados. Para a implantação prática, ante à resistência de usuários, integram-se ao sistema o serviço de censura e as autoridades policiais (para a aprovação 
de programas de diversões públicas, em que se exigia a exibição - como ora ocorre - dos recibos de pagamento dos direitos autorais) e normas sobre esses direitos passam a compor o respectivo cenário (em que o texto básico é o Dec. 20493, de 24-1-46).

A proliferação de associações e as vicissitudes encontradas na arrecadação trouxeram o Serviço de Defesa (SDDA) para a unificação (não conseguida) e, mesmo, a coligação mencionada, sempre sob o comando privado.

o Estado fiscalizava de modo indireto o setor e contribuía, com os mecanismos referidos, para a sua implantação prática, até que com os insistentes reclamos - dos próprios interessados e, mesmo, de estudiosos e de usuários - acabou por intervir na matéria, por meio da Lei 5988/73.

A cobrança era feita mediante tabelas, pelo sistema de pontuação, assinando-se protocolos de acordos com a radiodifusão e outros usuários.

\section{A instituição do CNDA pela Lei $5988 / 73$ e o controle do setor}

Com o advento da Lei 5988, de 14-12-73, sofreu o setor importantes modificações em sua estrutura, mediante a criação do Conselho Nacional de Direito Autoral (já citado) ; a instituição do ECAD e a regulamentação das associações (também mencionadas), passando a sofrer ingerência direta do Estado, por intermédio do CNDA (cuja previsão se deu, inicialmente, no projeto de Código citado, com o nome de "CoNDAC").

Fruto, pois, do denominado "dirigismo econômico" (V. o nosso artigo específico citado), o nascimento desse organismo inaugura uma nova fase no setor de direitos autorais no país, que fica, em conseqüência, sob o controle direto do Estado.

Sediado em Brasília e vinculado diretamente ao Ministro da Educação e Cultura, o Conselho sofreu duas principais formulações de estrutura, a primeira em sua instalação (Dec. de criação n. ${ }^{\circ}$ 76.275, de 15-11-75, e o Regimento interno; Portaria n..$^{\circ}$ 248, de 9-4-75) e a segunda - que lhe conferiu a composição atual - em fins de 1979 (texto já mencionado).

Cabem-lhe, consoante a Lei de regência, funções de fiscalização, consulta e assistência no que respeita a direitos de autor e dos que lhes são conexos (art. 116), com poderes normativos e de intervenção, tanto no ECAD, como nas associações, nas 
condições previstas (art. 117, espec. inciso III), bem como de decisão e de julgamento de processos administrativos relativos às matérias citadas (Dec. 84252/79) .

Trata-se de organismo que existe em outros países, também sob a forma de Conselho, ou, mesmo, de Oficinas centrais (nos países americanos e europeus, de um lado, e africanos, de outro), com atribuições de comandar a política do setor, em face de dificuldades que o complexo mecanismo operador oferece.

Composto, atualmente, de especialistas em Direito de Autor e com ampla vivência prática, vem o Conselho atuando decididamente no aprimoramento da área, em prol dos autores e da própria cultura nacional.

Divide-se em Câmaras especializadas, em razão da matéria (em número de três) e funciona como Colegiado nas decisões maiores e mesmo em grau de recurso. De suas decisões, nas condições previstas, cabe recurso administrativo ao Ministro.

\section{Submissão do ECAD ao CNDA}

Em função do exposto, tem-se claro que o Escritório Central (ECAD) e demais entidades do setor (associações, titulares e usuários) estão sujeitos à ação normativa, fiscalizadora e orientadora do Conselho.

Essa sujeição - como natural - cinge-se às disposições legais aplicáveis, de acordo com as quais deve o organismo - como, de resto, a sociedade em geral - pautar a sua atuação.

Especificamente em relação ao ECAD, deve-se anotar que a sua vida e a sua atuação estão mais de perto sob a ação do CNDA, em função da própria lei, que o atrelou, desde o nascedouro, ao órgão máximo do sistema administrativo autoral, submetendo a aprovação do respectivo estatuto à sua manifestação (art. 115).

A par disso, impôs-lhe diversas obrigações específicas, para facilitar a fiscalização e o controle do CNDA, a exemplo das associações (arts. 113, 114 e 115), conferindo àquele o poder de intervenção em seus negócios, sempre que descumprir obrigações legais, ou suas determinações, ou lesar direitos de seus associados (art. 117, inciso III) (poderes extensivos também aos negócios das associações, nas mesmas condições). E mais : os próprios preços - que têm os critérios definidos pelo CNDA — são oferecidos à sua homologação. 
Exerce, pois, o CNDA sobre o ECAD uma função normativa, geral e específica; uma função fiscalizadora de seus negócios e de sua administração; e uma função orientadora, quanto aos aspectos apontados.

Isso confere ao ECAD posição singular no contexto brasileiro de associações, porque, inobstante seja associação civil (conforme consta de sua regulamentação referida), sofre mais de perto a injunção estatal, por meio do CNDA, em face da disciplinação legal vigente.

Nesse sentido, aliás, é que, ante a irregularidades apontadas, em auditoria levada a efeito por técnicos especializados, o CNDA decretou intervenção no ECAD (pela Portaria 06, de 10-2-81), pelo prazo de cento e oitenta dias, e, nesse período, mediante a atuação de especialistas em diferentes áreas de administração de empresas, foram elaborados planos para o aperfeiçoamento da máquina interna do ECAD e também para o aprimoramento do sistema de arrecadação, por meio de cadastramentos de usuários, registro de obras, ampliação das faixas de arrecadação, treinamento e aperfeiçoamento do pessoal, aumento das capitais inseridas no sistema e outras medidas que, efetivadas, proporcionarão u'a maximização da arrecadiação em termos reais, com os frutos benéficos que todo o setor espera. Mantém-se, no entanto, o sistema de pontuação e o de tabela (a última homologada pelo CNDA, pela Res. 25, de 11-3-81 e ora em discussão com alguns usuários).

Estando por findar-se o prazo da intervenção, decidiu o Conselho, para efeito de prosseguimento e implantação dessas medidas e de realização de eleições para a administração do ECAD, nomear Supervisor Geral para gerir os seus destinos até a posse dos eleitos, prevista para 31-12-81.

Oxalá que os frutos dessa experiência sejam colhidos pelos representantes das associações - que, nessa transição, formarão um Conselho, para os fins de autorização autoral e o desempenho de funções outras de administração - e, posteriormente, pelos responsáveis pelo Escritório, aproveitando-os para imprimir ao ente dos autores a posição de verdadeiro defensor de seus direitos, e unindo-se todas as forças no sentido de atingir-se um congraçamento tal que lhe permita levar avante a difícil e espinhosa missão de captação de direitos autorais!...

Que se conscientizem todos de que a missão do administrador desses direitos deve voltar-se para os interesses das categorias representadas, pondo-se de lado problemas de ordem 
pessoal, para que, fortalecidos com a união, possam os intelectuais brasileiros receber a justa remuneração pela utilização de suas obras, em prol, afinal, do progresso da própria cultura da nação e da afirmação de seus valores básicos!. .

\section{V - Síntese conclusiva}

Dos direitos autorais de cunho patrimonial, destaca-se, no plano da música, o direito de execução pública, que consiste na prerrogativa que tem o autor de autorizar a utilização de sua obra, pelas formas possíveis, recebendo, em contrapartida, a remuneração correspondente.

Atuando, para tanto, por meio de associações de titulares, suas mandatárias, têm os autores encontrado enormes dificuldades para a efetivação desse direito, que se opera por intermédio de complexo mecanismo de coleta de dados e de processamento, baseado, principalmente, em amostragens, para a posterior distribuição do resultado aos titulares respectivos.

Ora, visando, entre nós - dada a diversidade de fórmulas encontradas em outros países - a centralizar-se a arrecadação desses direitos em um só organismo, criou-se o ECAD (Escritório Central de Arrecadação e Distribuição), que se insere em um sistema, instituído pela Lei 5988, de 14-12-73, sob cuja égide deve funcionar, tendo como organismo de cúpula o Conselho Nacional de Direito Autoral (CNDA).

Submetido - como as demais entidades do setor à sua ação normativa, fiscalizadora e orientadora - o ECAD passa por processo de aperfeiçoamento administrativo e operacional, que pretende imprimir-lhe estruturação que o capacite a funcionar mais eficazmente em prol dos direitos de seus representados, para o próprio desenvolvimento do setor e a conseqüente expansão da cultura do país.

\section{Bibliografia}

(específica)

ARe, Mario: L'oggetto del Diritto di Autore, Milano, Giuffrè, 1963.

BitTar, Carlos Alberto: Direito de Autor na obra feita sob encomenda, S.P., R.T., 1977.

Direito de Autor na obra publicitária, SP, RT, 1981.

Direito Autoral, em "Enciclopédia Saraiva do Direito" (verbete).

O Direito de Autor no plano das Liberdades Públicas, em "Justitia", n. ${ }^{\circ} 98$, p. 165 e segs. 
Boввіo, Pedro Vicente: O Direito de autor na criação musical, SP, Lex, 1951.

Bolla, Plinio: La radiodiffusione ed il diritto d'autore nella Convenzione riveduta a Bruxelles, dell'unione internazionale per la protezione delle opere letterarie ed artistiche, in "Scriti giuridici in onore di F. Carnelutti", Padova, Cedam, 1950, v. III.

Bollecker, Louis C.: Droit privé de la radiodiffusion, Paris, Sirey, 1934.

Caselli, Eduardo Piola: Trattato del Diritto di Autore e del contratto di edizione, Torino, Torinese, 1927.

Chaves, Antonio: Proteção internacional do Direito autoral de radiodifusão, SP, RT, 1952.

$A$ arrecadação do direito de autor na Europa, in "Revista da Faculdade de Direito", 1971, v. LXVI, p. 393 e segs.

O projeto brasileiro do Código de Direito de Autor e Direitos conexos, mesma Revista, p. 105 e s.

CoHeN, Naten: State regulation of musical copyright, in "Oregon Law Review", v. XVIII, fasc. 3 .

DebBasch, Charles: Traité du droit de la radiodiffusion, Paris, Lib. Générale, 1967.

Desbors, Henri: Le Droit d'auteur en France, Paris Dalloz, 1966.

DI Franco, Luigi: Proprietà industriale, letteraria ed artistica, Milano, SEI, 1936.

Fragola, Augusto: La cinematografia nella giurisprudenza, Padova, Cedam, 1966.

GÉrard, Paul Daniel: Los derechos de autor en la obra cinematográfica, trad., Barcelona, Ariel, 1958.

Greco, Paolo e Vercellone, Paolo: I diritti sulle opere del'ingegno, Torino, Torinese, 1974.

GRompone, Romeo: El Derecho de autor en Uruguay, Montevideo, Associación General de Autores de Uruguay, 1977.

LADAS, Stephen: The international protection of literary and artistic property, New York, Macmillan, 1938.

Movchet, Carlos: El dominio público pagante, Buenos Aires, Fondo Nacional de las Artes, 1970.

Padellaro, Giuseppe: Il Diritto di Autore (La disciplina giuridica degli strumenti di comunicazione sociale), Milano, Vallardi, 1972.

PariluI, Ricardo Antequera: Consideraciones sobre el Derecho de Autor, Buenos Aires, ed. próp., 1977.

Plaisant, Robert: Le droit des auteurs et des artistes exécutants, Paris, Delmas, 1970.

PoulaIN, Jean: La protection des émissions de radiodiffusion, Paris, Lib. Générale,1963.

RÉnAuld, J. G.: Droit d'auteur et contrat d'adaptation, Bruxelles, Larcier, 1955.

SANCTIS, Valerio de: Contrato di edizione-contratti di rappresentazione $e$ di esecuzione, Milano, Giuffrè 1965. 
352

Stolfi, Nicola: Il Diritto di Autore, Milano, S.E.I., 1932.

STOYANovitch, K.: Le droit d'auteur dans les rapports entre la France et les pays socialistes, Paris, Lib. Générale, 1959.

StRASCHINOv, Georges: Le droit d'auteur et des droits connexes en radiodiffusion, Bruxelles, Bruyant, 1950.

TARNec, Alain Le: Manuel de la propriété littéraire et artistique, Paris Dalloz, 1966. 